\title{
Successful Treatment with Denosumab of a Giant Cell Tumor of Bone in the Iliac Bone of an 84-Year-Old Man
}

\author{
Kensaku Yamaga," Satoshi Kuwamoto, † Daichi Mukunoki,* Mari Osaki* and Hideki Nagashima* \\ *Division of Orthopedic Surgery, Department of Sensory and Motor Organs, Faculty of Medicine, Tottori University, Yonago 683-8504, \\ Japan, and †epartment of Pathology, Tottori University Hospital, Yonago 683-8504, Japan
}

\begin{abstract}
We report a case of GCTB in an 84-year-old Japanese man who had a tumor in his left iliac bone and was treated safely with denosumab. The patient noticed a painful mass, with gradual enlargement, in his left low back next to the iliac region. Magnetic resonance imaging revealed that the tumor measured $94 \times 66 \times 90 \mathrm{~mm}$ and was located in the left iliac bone. Histologically, the tumor was composed of proliferative oval-shaped mononuclear cells, admixed with large number of osteoclast-like giant cells. Immunohistochemically, a strong positivity for histone $3.3 \mathrm{G} 34 \mathrm{~W}$ mutant protein was observed in the nuclei of the mononuclear cells, confirming the diagnosis of GCTB. Because it was considered as unresectable tumor, the patient was treated with denosumab without any side effects.
\end{abstract}

Key words denosumab; elderly; giant cell tumor of bone; histone $3.3 \mathrm{G} 34 \mathrm{~W}$; unresectable

Giant cell tumor of bone (GCTB) is a benign but locally aggressive primary bone neoplasm. GCTB represents $4-5 \%$ of all primary bone tumors. The peak incidence is between the ages of 20 and 45 years. ${ }^{1,2}$ In addition, the treatment of GCTB has changed dramatically since the availability of denosumab in recent years. Denosumab, a monoclonal antibody specific for a receptor activator of nuclear factor kappa-B ligand (RANKL), has attracted attention as a novel therapeutic strategy for GCTB. In particular, denosumab has become an extremely useful treatment for unresectable GCTB. Here, we described a case of GCTB in an 84-year-old Japanese man who had a tumor in his left iliac bone, which was treated with denosumab.

\footnotetext{
Corresponding author: Kensaku Yamaga, MD, PhD

kyamaga@tottori-u.ac.jp

Received 2020 July 15

Accepted 2020 August 12

Online published 2020 August 20

Abbreviations: CT, computed tomography; FDG, fluoro-2 deoxyD glucose; GCTB, giant cell tumor of bone; MRI, magnetic resonance imaging; PET, positron emission tomography; RANKL, receptor activator of nuclear factor kappa-B ligand; TRACP-5b, tartrate-resistant acid phosphatase $5 \mathrm{~b}$
}

\section{PATIENT REPORT}

An 84-year-old Japanese man without a history of any previous traumatic episodes, noticed a painful mass in the left low back region. The mass gradually enlarged over a period of two months. The patient was referred to our hospital for evaluation and treatment by his primary care doctor. Physical examination showed that the mass was a tumor localized to the left low back in the iliac region, of about $8 \mathrm{~cm}$ in diameter, hard and unmovable with mild tenderness. No abnormality was observed in the skin. The patient had a medical history of diabetes mellitus and chronic renal failure. His family history was unremarkable. Laboratory analysis revealed that white blood cell counts and lactate dehydrogenase levels were normal, alkaline phosphatase level was $514 \mathrm{U} / \mathrm{L}$ (normal range: 106-332 U/L), Serum calcium level was $8.9 \mathrm{mg} / \mathrm{dL}$ (normal range: $8.8-10.1 \mathrm{mg} / \mathrm{dL}$ ), blood urea nitrogen was $22.0 \mathrm{mg} / \mathrm{dL}$ (normal range: $8-20 \mathrm{mg} / \mathrm{dL}$ ), creatinine was $1.16 \mathrm{mg} / \mathrm{dL}$ (normal range: $0.65-1.07 \mathrm{mg}$ / $\mathrm{dL}$ ), C-reactive protein was $0.66 \mathrm{mg} / \mathrm{dL}$ (normal level < $0.15 \mathrm{mg} / \mathrm{dL}$ ), hemoglobin A1C level was $6.9 \%$ (normal range: $4.9-6.0 \%$ ), and tartrate-resistant acid phosphatase $5 \mathrm{~b}$ (TRACP-5b) was $1500 \mathrm{mU} / \mathrm{dL}$ or higher (normal range: $170-590 \mathrm{mU} / \mathrm{dL}$ ). Plain radiography showed an expansile osteolytic lesion with partial marginal sclerosis in the left iliac bone (Fig. 1). Computed tomography (CT) also revealed a ballooning osteolytic lesion involving soft tissues and the sacroiliac joint with a partially lacking sclerotic rim (Fig. 2A). The tumor demonstrated an abnormal uptake of 2-[18 F] fluoro-2 deoxy-D glucose (FDG) on positron emission tomography (PET)$\mathrm{CT}$, with a maximum standardized uptake value of 11.4 (Fig. 2B). Magnetic resonance imaging (MRI) revealed that the tumor measured $94 \times 66 \times 90 \mathrm{~mm}$, was located in the left iliac bone invading the gluteus maximus, gluteus medius, paravertebral muscle, and sacral bone through the sacroiliac joint. It was partially lobulated and displayed a relatively clearly defined margin (Fig. $3)$. T1-weighted imaging exhibited iso low-signal intensity in the tumor region (Fig. 3A). In contrast, T2weighted imaging exhibited inhomogeneous high signal intensity within low signal intensity of the tumor (Fig. 3B). Enhanced MRI exhibited inhomogeneous enhancement within the lesion (Fig. 3C). Whole body PET-CT 


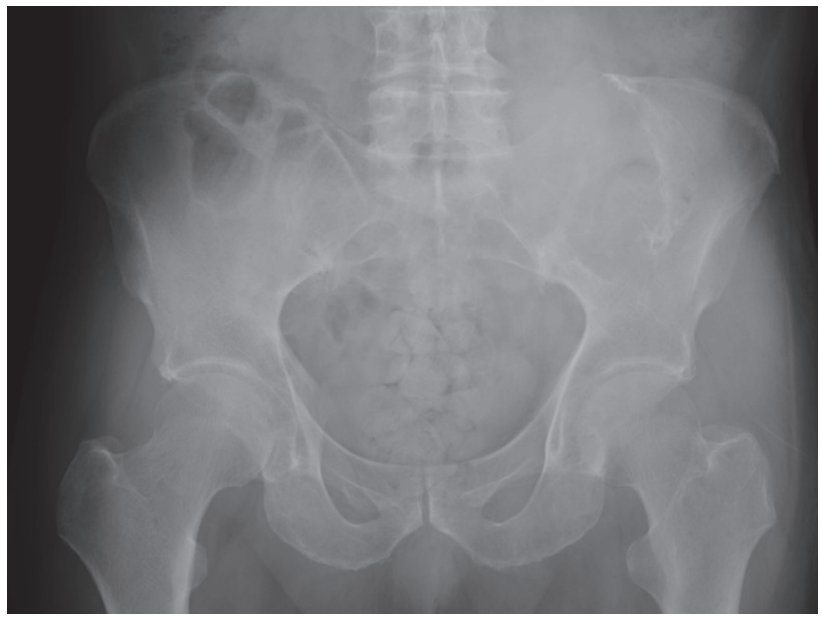

Fig. 1. Plain radiography of the pelvis showing an expansile osteolytic lesion with a partial marginal sclerosis in the left iliac bone.

showed no evidence of another tumor.

Based on the clinical findings and imaging examination, we initially considered this tumor to be a malignant tumor such as metastatic bone tumor of an unknown primary origin and primary bone sarcoma; however, an option of GCTB was also included in the differential diagnosis. A core needle biopsy was performed for histological examination, which revealed a giant cell-rich lesion. Although GCTB was suspected, it was difficult to exclude other neoplastic/ nonneoplastic lesions such as giant cell reparative granuloma, giant cell-rich osteosarcoma, and giant cell variant of undifferentiated pleomorphic sarcoma of bone. Thereafter, an open biopsy was performed and a yellow lesion with an elastic-soft consistency was obtained. Histological examination showed a tumor similar to that in the initial biopsy, composed of ovalshaped mononuclear cells admixed with a large number of osteoclast-like giant cells (Figs. 4A and B). The giant cells were evenly distributed within the lesion and had a variable number of nuclei (up to 50) and abundant eosinophilic cytoplasm. Mitotic cells were occasionally observed among the mononuclear cells (up to 2/high power field) but these were never atypical. Marked nuclear pleomorphism and hyperchromasia were not observed. Immunohistochemistry using an anti-histone 3.3 G34W mutant antibody (clone RM263; dilution, 1:100; RevMAb Biosciences, South San Francisco, CA) was performed, and a strong positive staining in the nucleus was observed in the mononuclear cells (Fig. 4C). The tumor was finally diagnosed definitively as GCTB of the iliac bone based on the clinical, histological, and immunohistochemical examinations.

We considered that surgery would be associated with high risks after evaluating the patient's age, tumor size, anatomical location, and functional loss due to surgery. Therefore, we administered a treatment with denosumab, a monoclonal antibody specific to RANKL. The patient received a subcutaneous injection of denosumab $(120 \mathrm{mg})$ on days $0,7,14,28$, and thereafter, every four weeks concomitantly taking orally daily supplements containing calcium and magnesium. The patient received a total of 11 subcutaneous injections
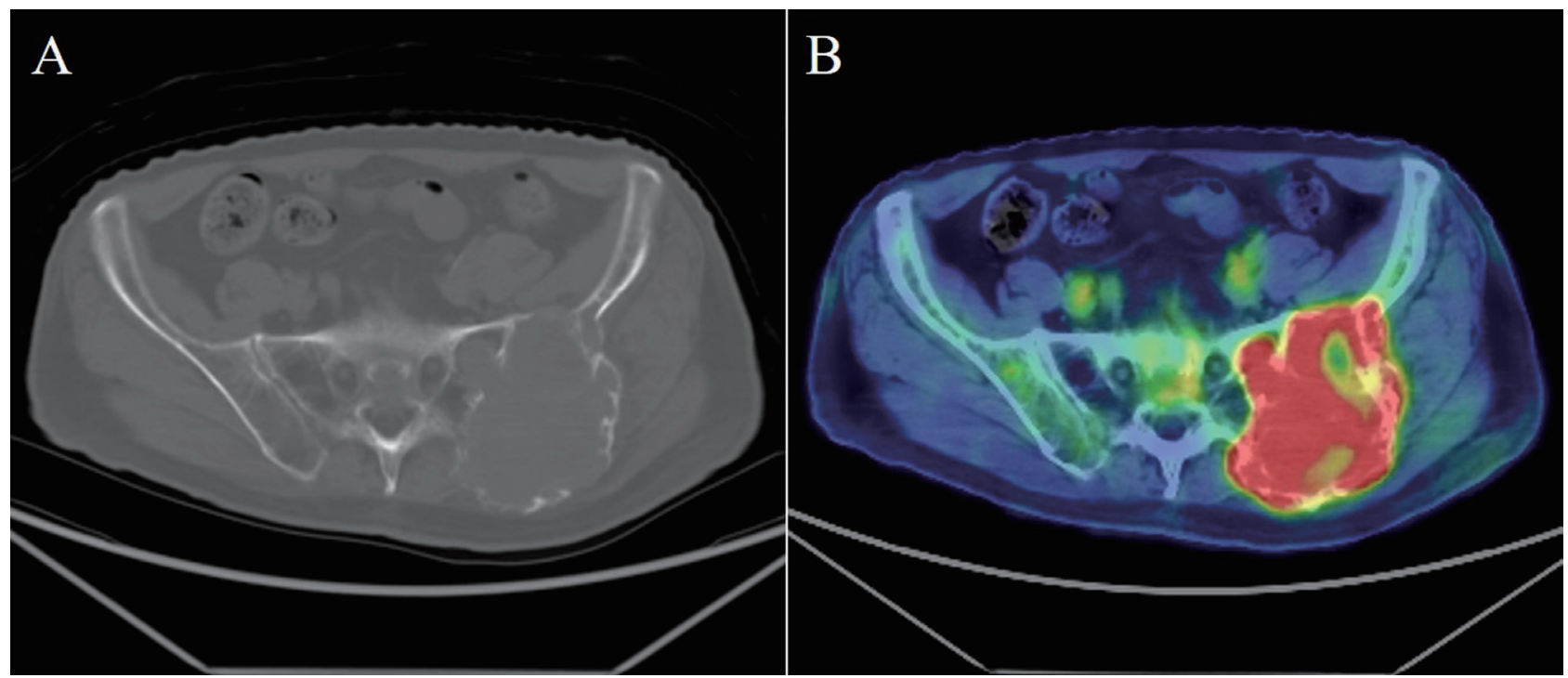

Fig. 2. (A) Plain CT reveals that the tumor has a ballooning osteolytic lesion involving soft tissues and the sacroiliac joint with a partially lacking sclerotic rim. (B) The maximum standardized uptake value of the tumor was 11.4 on positron emission tomography-CT. CT, computed tomography. 

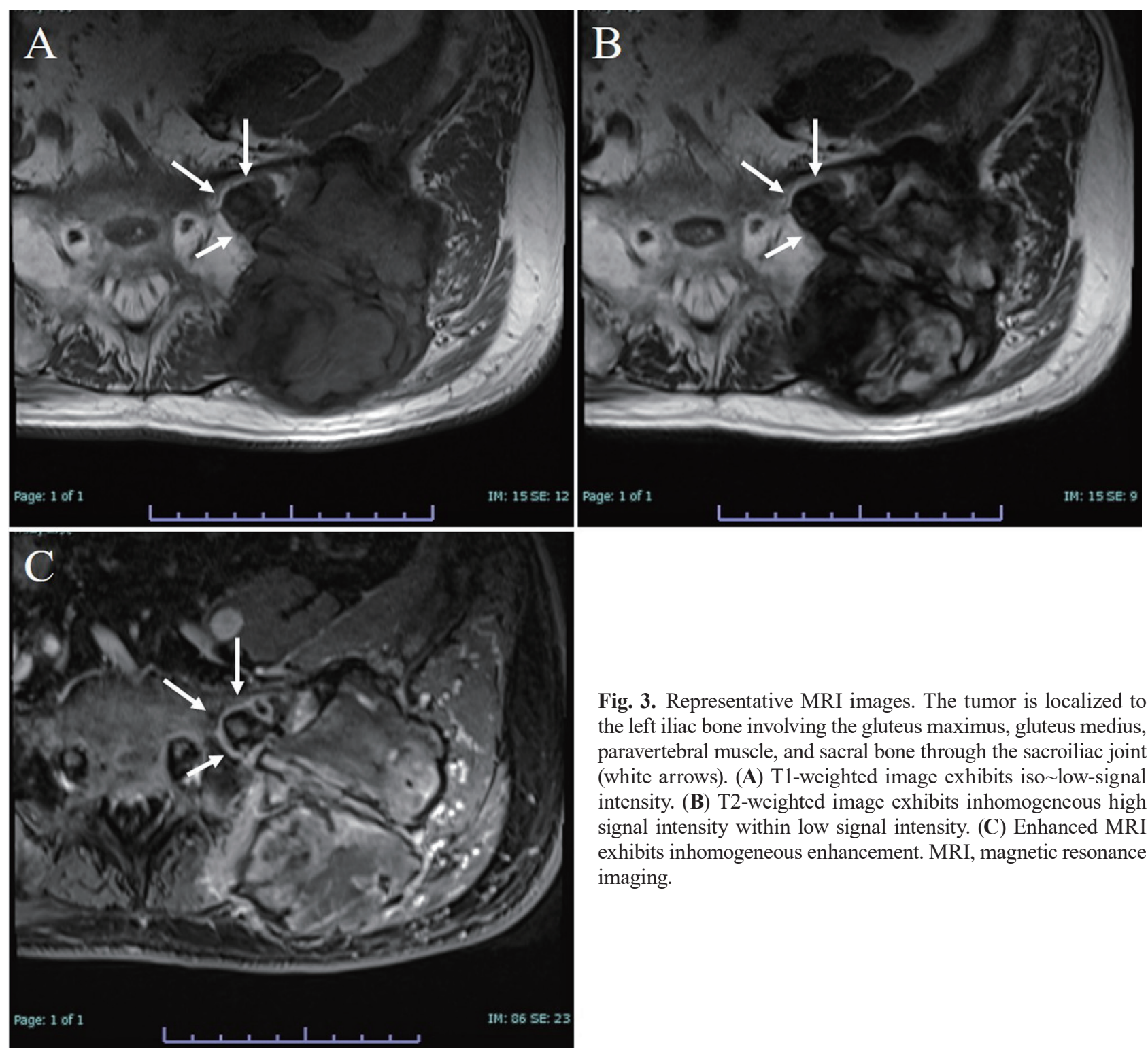

Fig. 3. Representative MRI images. The tumor is localized to the left iliac bone involving the gluteus maximus, gluteus medius, paravertebral muscle, and sacral bone through the sacroiliac joint (white arrows). (A) T1-weighted image exhibits iso low-signal intensity. (B) T2-weighted image exhibits inhomogeneous high signal intensity within low signal intensity. (C) Enhanced MRI exhibits inhomogeneous enhancement. MRI, magnetic resonance imaging.

of denosumab in ten months and this treatment is still ongoing as of now. The patient's pain has gradually improved. Plain radiography showed a structure of a soap bubble appearance with marginal ossification in the expansile lesion in the left iliac bone (Fig. 5). In CT imaging, the tumor size appeared slightly decreased, and the ossification of the tumor rim became remarkable (Fig. 6). After four cycles of subcutaneous injections of denosumab, TRACP-5b levels decreased to normal values $(119 \mathrm{mU} / \mathrm{dL})$ and remained within the normal range over the next nine months. Serum calcium levels were normal throughout the treatment. The patient had experienced none of the known side effects of denosumab. The present course of treatment has been uneventful, with no evidence of recurrence or metastasis.

\section{DISCUSSION}

GCTB is a benign but locally aggressive primary bone neoplasm and represents $4-5 \%$ of all primary bone tumors. The peak incidence is between the ages of 20 and 45 years. ${ }^{1,2}$ GCTB is very unusual in patients older than age $55 .{ }^{1}$ The occurrence of GCTB in patients who are 55 years of age and older is well documented, comprising approximately $1.6 \%$ to $35 \%$ of case series in international population-based studies. ${ }^{3-16}$ There are two main previously published reports that described GCTB in elderly patients. ${ }^{17,}{ }^{18}$ McCarthy et al. ${ }^{17}$ reported ten such cases of patients whose age ranged from 62 to 78 years. They concluded that the behavior of GCTB in elderly patients was similar to that of lesions in the more commonly involved younger patients. Broehm et al. ${ }^{18}$ reported 34 such cases in patients ranging in age 

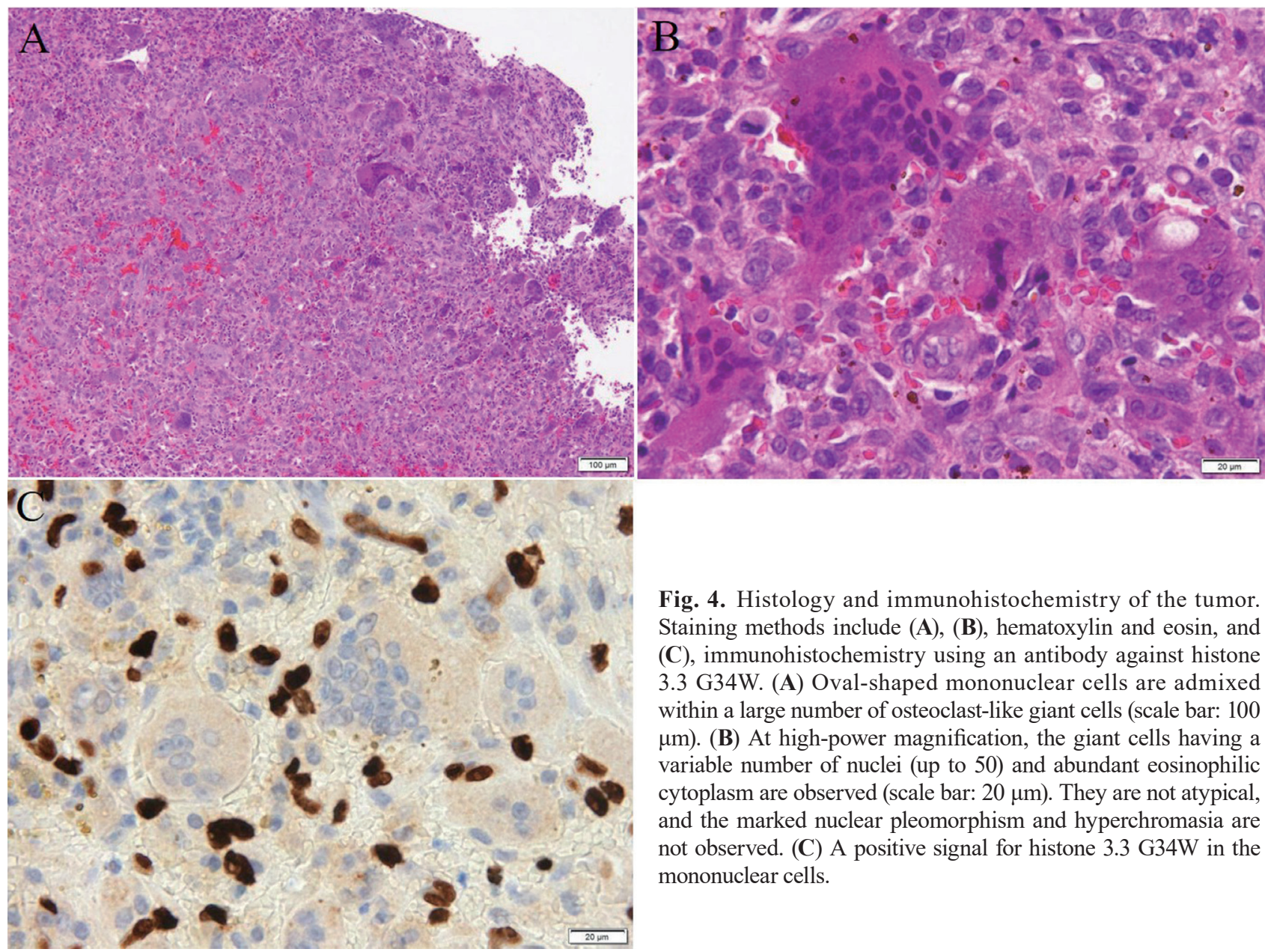

Fig. 4. Histology and immunohistochemistry of the tumor. Staining methods include (A), (B), hematoxylin and eosin, and (C), immunohistochemistry using an antibody against histone 3.3 G34W. (A) Oval-shaped mononuclear cells are admixed within a large number of osteoclast-like giant cells (scale bar: 100 $\mu \mathrm{m})$. (B) At high-power magnification, the giant cells having a variable number of nuclei (up to 50) and abundant eosinophilic cytoplasm are observed (scale bar: $20 \mu \mathrm{m}$ ). They are not atypical, and the marked nuclear pleomorphism and hyperchromasia are not observed. (C) A positive signal for histone $3.3 \mathrm{G} 34 \mathrm{~W}$ in the mononuclear cells.

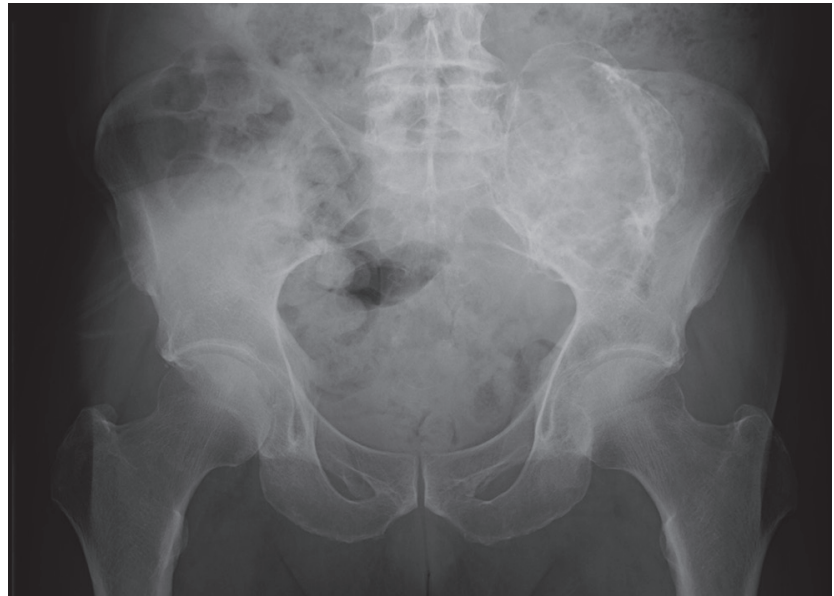

Fig. 5 . Plain radiography of the pelvis ten months after starting the treatment shows a structure with a soap bubble appearance with marginal ossification in the expansile lesion.

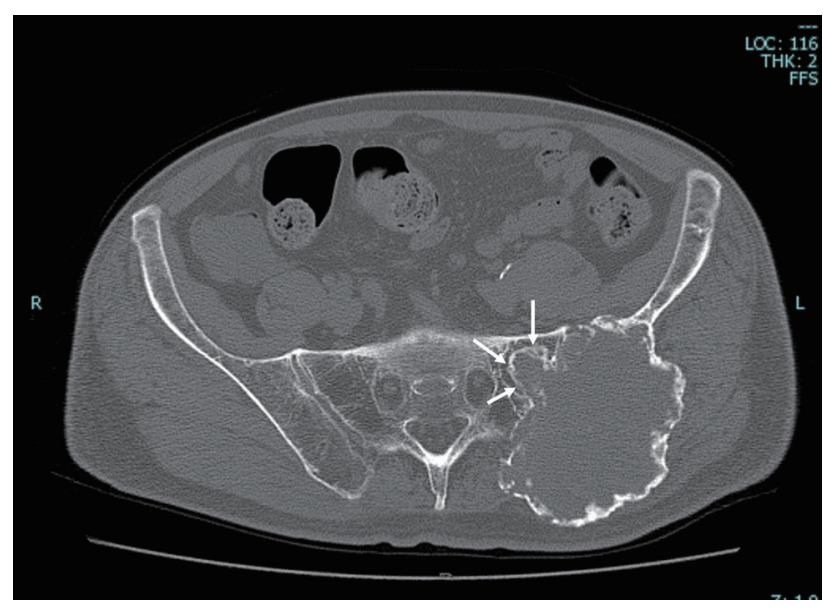

Fig. 6. CT imaging ten months after starting treatment revealed that the tumor size was slightly decreased and the ossification of the tumor rim became remarkable, especially, on the lesion involving the sacrum (white arrows) compared with that before treatment. CT, computed tomography. 
from 56 to 83 years. They demonstrated that fibrosis and reactive bone were common, potentially leading to diagnostic confusion of GCTB in elderly patients. Cytogenetically, GCTB has recently been shown to harbor $H 3 F 3 A$ (histone 3.3) mutations in virtually all cases $(96 \%)$, with G34W accounting for the vast majority of the mutant variants, and immunohistochemical detection of the G34W mutant in the nuclei of the mononuclear cells has been shown to be a powerful adjunct assay in the diagnosis of GCTB. ${ }^{19}$ The utility of histone $3.3 \mathrm{G} 34 \mathrm{~W}$ immunohistochemistry was further confirmed by the present case, in which the patient's age was very unusual for GCTB occurrence.

Until recently, there was no method for GCTB treatment other than surgery, but the availability of denosumab has dramatically changed this treatment strategy. Denosumab (anti-RANKL antibody) is a novel agent, a fully human monoclonal antibody that inhibits osteoclastic-medicated bone resorption by binding to osteoblast-produced RANKL. By this mechanism, denosumab induces tumor reduction and bone reformation in patients with GCTB. ${ }^{20}$ Denosumab has proven to be a very effective treatment for unresectable GCTB.

The present case was a GCTB in an 84-year-old man. Because of the atypical age at the onset, a definitive diagnosis of GCTB was made with care. Histone 3.3 G34W immunostaining was especially useful for diagnosis. Because the tumor was huge and located in the iliac bone, we judged it unresectable and treated it with denosumab. Denosumab was effective and safe to use without any side effects. The patient presented in this case is thought to belong to the oldest age group of GCTB patients, and to the best of our knowledge, he is the oldest among patients with GCTB whose diagnosis was molecularly-confirmed by the detection of histone 3.3 mutants. The oldest patient with GCTB was 88 years old, reported by Amelio et al. in a populationbased study of 310 patients in Sweden. ${ }^{3}$ However, the site of tumor occurrence and the treatment strategy of that patient was not indicated and is currently unknown.

Ancillary testing for histone $3.3 \mathrm{G} 34 \mathrm{~W}$ by immunohistochemistry was a useful adjunct assay for the successful diagnosis of GCTB. Although they may be rare, GCTB should be considered in the differential diagnosis of bone tumors for the elderly. Additionally, the present case highlights the efficacy and safety of denosumab treatment in elderly patients with GCTB.

Consent for publication: The patient was fully informed that his data would be submitted for publication.

The authors declare no conflict of interest.

\section{REFERENCES}

1 Dorfman HD, Crerniak B. Giant-cell rich lesions in bone tumors. Bone Tumors. St. Louis: Mosby; 1998. p. 559-606.

2 Athanasou NA, Bansal M, Forsyth R, Reid RP, Sapi Z. Giant cell tumour of bone. In: Fletcher CDM, Bridge JA, Hogendoorn PCW, Mertens F, editors. World Health Organization Classification of Tumours. Soft Tissue and Bone. 4th ed. Lyon: IARC Press; 2013. p. 321-4.

3 Amelio JM, Rockberg J, Hernandez RK, Sobocki P, Stryker S, Bach BA, et al. Population-based study of giant cell tumor of bone in Sweden (1983-2011). Cancer Epidemiol. 2016;42:829. DOI: 10.1016/j.canep.2016.03.014, PMID: 27060625

4 Lin F, Hu Y, Zhao L, Zhang H, Yu X, Wang Z, et al. The epidemiological and clinical features of primary giant cell tumor around the knee: A report from the multicenter retrospective study in china. J Bone Oncol. 2016;5:38-42. DOI: 10.1016/ j.jbo.2016.02.001, PMID: 26998425

5 Niu X, Xu H, Inwards CY, Li Y, Ding Y, Letson GD, et al. Primary bone tumors: epidemiologic comparison of 9200 patients treated at Beijing Ji Shui Tan Hospital, Beijing, China, with 10165 patients at Mayo Clinic, Rochester, Minnesota. Arch Pathol Lab Med. 2015;139:1149-55. DOI: 10.5858/ arpa.2014-0432-OA, PMID: 25978765

6 Rockberg J, Bach BA, Amelio J, Hernandez RK, Sobocki P, Engellau J, et al. Incidence trends in the diagnosis of giant cell tumor of bone in Sweden since 1958. The Journal of Bone and Joint Surgery. 2015;97:1756-66. DOI: 10.2106/JBJS.O.00156, PMID: 26537163

7 Baena-Ocampo LC, Ramirez-Perez E, Linares-Gonzalez LM, Delgado-Chavez R. Epidemiology of bone tumors in Mexico City: retrospective clinicopathologic study of 566 patients at a referral institution. Ann Diagn Pathol. 2009;13:16-21. DOI: 10.1016/j.anndiagpath.2008.07.005, PMID: 19118777

8 Campanacci M, Baldini N, Boriani S, Sudanese A. Giantcell tumor of bone. The Journal of Bone \& Joint Surgery. 1987;69:106-14. DOI: 10.2106/00004623-198769010-00018, PMID: 3805057

9 Dahlin DC. Caldwell Lecture. Giant cell tumor of bone: highlights of 407 cases. AJR Am J Roentgenol. 1985;144:95560. DOI: 10.2214/ajr.144.5.955, PMID: 3872579

10 Larsson SE, Lorentzon R, Boquist L. Giant-cell tumor of bone. A demographic, clinical, and histopathological study of all cases recorded in the Swedish Cancer Registry for the years 1958 through 1968. The Journal of Bone \& Joint Surgery. 1975;57:167-73. DOI: 10.2106/00004623-19755702000007, PMID: 1112843

11 Goldenberg RR, Campbell CJ, Bonfiglio M. Giant-cell tumor of bone. An analysis of two hundred and eighteen cases. The Journal of Bone \& Joint Surgery. 1970;52:619-64. DOI: 10.2106/00004623-197052040-00001, PMID: 5479455

12 Mnaymneh WA, Dudley HR, Mnaymneh LG. Giant-cell tumor of bone: an analysis and follow-up study of the fortyone cases observed at the Massachusetts General Hospital between 1925 and 1960. The Journal of Bone \& Joint Surgery. 1964;46:63-75. DOI: 10.2106/00004623-196446010-00006, PMID: 14104315

13 Werner M. Giant cell tumour of bone: morphological, biological and histogenetical aspects. Int Orthop. 2006;30:484-9. DOI: 10.1007/s00264-006-0215-7, PMID: 17013643

14 McGrath PJ. Giant-cell tumour of bone: an analysis of fiftytwo cases. J Bone Joint Surg Br. 1972;54-B:216-29. DOI: 10.1302/0301-620X.54B2.216, PMID: 5034822 
15 Liede A, Bach BA, Stryker S, Hernandez RK, Sobocki P, Bennett B, et al. Regional variation and challenges in estimating the incidence of giant cell tumor of bone. The Journal of Bone and Joint Surgery. 2014;96:1999-2007. DOI: 10.2106/ JBJS.N.00367, PMID: 25471915

16 Gupta R, Seethalakshmi V, Jambhekar NA, Prabhudesai S, Merchant N, Puri A, et al. Clinicopathologic profile of 470 giant cell tumors of bone from a cancer hospital in western India. Ann Diagn Pathol. 2008;12:239-48. DOI: 10.1016/ j.anndiagpath.2007.09.002, PMID: 18620989

17 McCarthy EF, Weber KL. Giant cell tumor of bone in elderly patients: a study of ten patients. Iowa Orthop J. 2009;29:7982. PMID: 19742090
18 Broehm CJ, Inwards CY, Al-Ibraheemi A, Wenger DE, Jenkins SM, Jin L, et al. Giant Cell Tumor of Bone in Patients 55 Years and Older: A Study of 34 Patients. Am J Clin Pathol. 2018;149:222-33. DOI: 10.1093/ajcp/aqx155, PMID: 29425276

19 Amary F, Berisha F, Ye H, Gupta M, Gutteridge A, Baumhoer D, et al. H3F3A (Histone 3.3) G34W Immunohistochemistry: A Reliable Marker Defining Benign and Malignant Giant Cell Tumor of Bone. Am J Surg Pathol. 2017;41:1059-68. DOI: 10.1097/PAS.0000000000000859, PMID: 28505000

20 Branstetter DG, Nelson SD, Manivel JC, Blay JY, Chawla S, Thomas DM, et al. Denosumab induces tumor reduction and bone formation in patients with giant-cell tumor of bone. Clin Cancer Res. 2012;18:4415-24. DOI: 10.1158/1078-0432.CCR12-0578, PMID: 22711702 